9. Hickman, S., and Neufeld, E. F.: A hypothesis for I-cell disease: Defective hydrolases that do not enter lysosomes. Biochem. Biophys. Res. Commun., 49: 992 (1972).

10. Leroy, J. G., and De Mars, R. I.: Mutant enzymatic and cytological phenotypes in cultured human fibroblasts. Science, 157: 804, (1967).

11. Lightbody, J., Wiesmann, U., Hadorn, B., and Herschkowitz, N.: I-cell disease: Multiple lysosomal enzyme defect. Lancet, $i$ : 451 (1971).

12. Lowry, O. H., Rosebrough, N. J., Farr, A. L., and Randall, R. J.: Protein measurement with the folin phenol reagent. J. Biol. Chem., 193: 795 (1951).

13. Neufeld, E. F., and Cantz, M. U.: Corrective factors for inborn errors of mucopolysaccharide metabolism. Ann. N. Y. Acad. Sci., 72: 580 (1971).

14. Paigen, K.: In: M. Recheigl: Enzyme Synthesis and Degradation in Mammalian Systems, pp. 1-46 (Karger, Basel 1971).

15. Tondeur, M., Vamos-Hurwitz, E., Mockel-Pohl, S., Demeure, J. P., Cremer, N., and Loeb, H.: Clinical, biochemical and ultrastructural studies in cases of chondrodystrophy presenting the I-cell phenotype in tissue culture. J. Pediat., 79: 366 (1971).

16. Van Hoof, F., and Hers, H. G.: The abnormalities of lysosomal enzymes in mucopolysaccharidoses. Eur. J. Biochem., 7: 34 (1968).

17. Walbaum, R., Dehaene, P., Scharfman, W., Farriaux, J. P., Tondeur, M., Vamos-Hurwitz, E., Kint, J. A., and Van Hoof, F.: La mucolipidose de type II (I-cell disease). Arch. Franc. Pédiat.,
30: 577 (1973).

18. Wiesmann, U. N., Lightbody, J., Vassella, F., and Herschkowitz, N. N.: Multiple lysosomal enzyme deficiency due to enzyme leakage? New Engl. J. Med., 284: 109 (1971).

19. Wiesmann, U. N., Eto, Y., and Herschkowitz, N: To be published.

20. Wiesmann, U. N., Rossi, E. E., and Herschkowitz, N. N.: Correction of the defective sulfatide degradation in cultured fibroblasts from patients with MLD. Acta Paediat. Scand., 61: $296(1972)$.

21. Wiesmann, U. N., Vassella, F., and Herschkowitz, N.: I-cell disease: Leakage of lysosomal enzymes into extracellular fluids. New Engl. J. Med., 285: 1090 (1971).

22. Wiesmann, $U, N$, Vassella, $F$, and Herschkowitz, N. N.: Mucolipodosis II (I-cell disease): A clinical and biochemical study. Acta Paediat. Scand., 63: 9 (1973).

23. Winterburn, P. J., and Phelps, C. F.: The significance of glycosylated proteins. Nature, 236: 147 (1972).

24. We thank Dr. Loeb, Brussels, and Dr. E. E. Neufeld, National Institutes of Health, Bethesda, Md., for supplying us with cultures from their patients.

25. This work was supported by Swiss National Foundation Grants nos. $3.407 .70,3.697 .71$, and 5072.3 and by the Hochschulstiftung Bern.

26. Requests for reprints should be addressed to: U. N. Wiesmann, M.D., Department of Pediatrics, Division of Cell Biology and Neurochemistry, University of Berne, Berne, Switzerland.

27. Accepted for publication July 2, 1974.

\title{
Amniotic Fluid Cell Culture I. Experimental Design for Evaluating Cell Culture Variables: Determination of Optimal Fetal Calf Serum Concentration
}

\author{
JEANETTE S. FELIX, RICHARD A. DOHERTY, ${ }^{(24)}$ HENRY T. DAVIS, AND SUSAN C. RIDGE \\ Departments of Pediatrics, Radiation Biology/Biophysics, Divisions of Genetics, Biostatistics, \\ University of Rochester School of Medicine and Dentistry, Rochester, New York, USA
}

\section{Extract}

We have developed a randomized, multivariable block design for quantitative evaluation of conditions for amniotic fluid (AF) cell attachment to culture surface and subsequent growth rate. We report the use of this method to determine optimal fetal calf serum (FCS) concentration in the culture medium. The AF cell growth, in the form of discrete colonies, was scored by counting the number of colonies and measuring their diameters. A two-way analysis of variance of the preliminary experiment data $(5-30 \%$ FCS $)$ demonstrated a significant difference among AF cells grown at different percentages of FCS $(P<0.0005)$. From a studentized range analysis we concluded that $5 \%$ FCS is inferior to higher percentages. No difference was demonstrated among 15-30\%
FCS. Based on these data, a supplementary experiment was planned to compare 10 and $15 \%$ FCS. The $15 \%$ FCS yielded at least 0.31 colonies $/ \mathrm{ml}$ AF more than did 10\% FCS. We conclude that $15 \%$ FCS is sufficient for AF cell culture using our technique. Close agreement of the estimates of standard deviation of the preliminary and supplementary experiments (7.38 and 7.25) indicates that the assumptions required for our experimental design are correct and that our technical procedures are highly reproducible.

A larger series of 76 AF specimens was used to correlate patient data with AF cell growth. We have shown that AF cell growth is independent of: (1) gestational age between 11 and 24 weeks; (2) maternal age between 14 and 42 years; (3) maternal ethnic group. A mean of 6 colonies/ml AF was obtained. 


\section{Speculation}

Development of highly efficient and reliable procedures for culturing AF cells depends upon statistically valid, quantitative assessment of all variables surrounding amniocentesis and subsequent cell culture. Using a randomized, multivariable block design, optimal culture procedures and conditions can be established and standardized which result in increased culture success rate and decreased time requirement for prenatal detection.

Early in the second trimester of pregnancy, cells of fetal origin can be obtained by transabdominal amniocentesis with low risk to fetus and mother. It is now possible to determine with nearly $100 \%$ accuracy fetal chromosomal abnormalities as well as more than 50 inherited biochemical disorders (10). Growth of cells in culture is required for most of these analyses.

Standard, optimal cell culture procedures are urgently needed to provide the reliability and sensitivity essential to prenatal diagnosis. Yet there has been very little quantitative evaluation of cell culture variables. Although procedures for in vitro culture of human diploid cells vary greatly, most laboratories are successful in establishing cell cultures. Apparently there is a wide range of "acceptable" but not necessarily optimal conditions. Cell cultures often are initiated from an abundant source of cells. However, a very different situation obtains when cells from AF are cultured. At 16 weeks of gestational age, the cellular content of $\mathrm{AF}$ is estimated to be approximately $1.2 \times 10^{4} \mathrm{cells} / \mathrm{ml}$ AF (5). An average of 6 colonies $/ \mathrm{ml} \mathrm{AF}$ is observed at 16 weeks of gestational age in this laboratory, i.e., 1 cultivable cell (or clump of cells) in 2,000 .

Determination of optimal conditions for AF cell culture is of crucial importance because of the small numbers of cultivable cells and the need for rapid growth due to stringent temporal constraints which bind prenatal diagnostic amniocentesis and elective abortion. We have developed a sensitive, randomized, multivariable block design to determine optimal conditions for cell attachment to culture surface and subsequent growth rate. We report the determination of optimal fetal calf serum concentration in the culture medium and correlations of AF cell growth with gestational age, maternal age, and maternal ethnic origin.

\section{METHODS AND MATERIALS}

\section{AF SPECIMENS}

Eighty-eight specimens were obtained by transabdominal amniocentesis prior to induction of elective abortion by saline injection between 11 and 24 weeks of gestational age. AF was sent to us at ambient temperature in sterile, unsiliconized, Wheaton glass bottles (16). Eighty AFs were put into culture within $8 \mathrm{hr}$ after amniocentesis. Eight AFs were cultured at 15,24 , or $48 \mathrm{hr}$ after amniocentesis. Those AFs containing visible amounts of erythrocytes were not used.

\section{CULTURE CONDITIONS}

All cells were cultured in 35-mm plastic petri dishes (17), at $37^{\circ}$, in a 14 cubic foot Wedco incubator (18). The incubator's atmosphere of $3 \% \mathrm{CO}_{2}$ in air (total gas flow rate, 4.3 liters $/ \mathrm{min}$ ) produced $\mathrm{pH} 7.4$ in equilibrated AF. Medium F10 (19) was adjusted to $20 \mathrm{mM} \mathrm{NaHCO}$ in order to obtain pH 7.4 after mixture with FCS (19) and equilibration in the incubator. The $\mathrm{pH}$ of the medium with FCS, checked weekly, was between 7.4 and $7.5(20)$.
EXPERIMENTAL DESIGN

An "experimental block" is defined as a set of culture dishes, all of which are inoculated with cells fron the same sample of AF and which are assigned to a "treatme at group" (e.g., a particular concentration of FCS in the medium). In the preliminary equipment, a block comprised 18 dishes: 3 replicate dishes in each of six treatment groups $(5,10,15,20$, 25 , and $30 \%$ FCS). A block in the supplementary experiment contained 6 dishes: 3 replicate dishes in each of two treatment groups (10 and $15 \%$ FCS).

An AF was used only if its volume was sufficient for one or more complete blocks. To initiate a block, $2 \mathrm{ml}$ thoroughly mixed AF plus penicillin (100 units/ml) and streptomycin $(100 \mu \mathrm{g} / \mathrm{ml})$ were pipetted into each culture dish. Supplemental nutrients or FCS were not added $(4,7)$. After $24 \pm 1$ $\mathrm{hr}$, after cells had attached to the dish bottom, AF was replaced with medium F10 containing designated amounts of FCS and antibiotics as above. This range of FCS concentration did not change the medium $\mathrm{pH}$ more than $0.1 \mathrm{pH}$ unit. On day 7 the medium was replaced with fresh medium containing the assigned percentage of FCS. On day 14 the cells were rinsed twice with $0.9 \% \mathrm{NaCl}$, fixed for $15 \mathrm{~min}$ in absolute methanol, and air dried. These dish bottoms were stained for $2 \mathrm{~min}$ with $0.25 \%$ toluidine blue in $0.1 \mathrm{M}$ sodium citrate buffer $(\mathrm{pH} \mathrm{6.0)}$, rinsed in water, air dried, and scored.

\section{GROWTH ASSAY}

Cellular growth was primarily in the form of discrete colonies and was scored blindly by one of two persons who counted the number of colonies and measured their diameters using a dissecting microscope. A colony was defined as a group of more than 50 cells, which were either densely confluent or spread sparsely in a monolayer. Scattered cells, defined either as groups of $10-50$ cells or as areas with $<50$ cells $/ 2 \mathrm{~mm}$ diameter, were recorded but were not included for analysis, because their origin is unclear. The number of scattered cells was similar in all FCS concentrations. Clusters of less than 10 cells were not recorded.

\section{RESULTS}

\section{PRELIMINARY EXPERIMENT (5-30\% FCS)}

An experiment of 17 blocks was performed using 16 different AF samples. Figure 1 displays the mean number of colonies formed $\left( \pm \mathrm{SD}_{\overline{\mathrm{x}}}\right)$ in medium containing $5-30 \% \mathrm{FCS}$.

A standard two-way analysis of variance performed on the data demonstrates: (1) a population SD of 7.38 ; (2) a significant difference among the treatment group means ( $P$ $<0.0005$ ); (3) a significant difference among blocks, i.e., the number of colonies formed within a treatment group varies greatly among AF specimens $(P<0.0005)$. This observation emphasizes the need to use a block design for AF cell culture experiments.

The studentized range procedure (9) was used to test for significance of differences between all possible pairs of treatment means (Table 1). One-sided levels of significance were calculated to test whether or not higher concentrations of FCS yielded more growth. These analyses can also be performed quickly and accurately with studentized range graph paper (3).

Colony diameters ranged between 1 and $14 \mathrm{~mm}$ for all FCS percentages. The mean size of dense colonies was $4.1 \mathrm{~mm}$ in $5 \% \mathrm{FCS}$ and 4.8 to $5.0 \mathrm{~mm}$ in the higher FCS percentages. The mean diameter of sparse colonies was $2.3 \mathrm{~mm}$ in $5 \%$ FCS and 2.6 to $2.8 \mathrm{~mm}$ in the higher FCS percentages. The distribution of colony sizes in 10-30\% FCS was similar, while a larger proportion of colonies in 5\% FCS was small. 


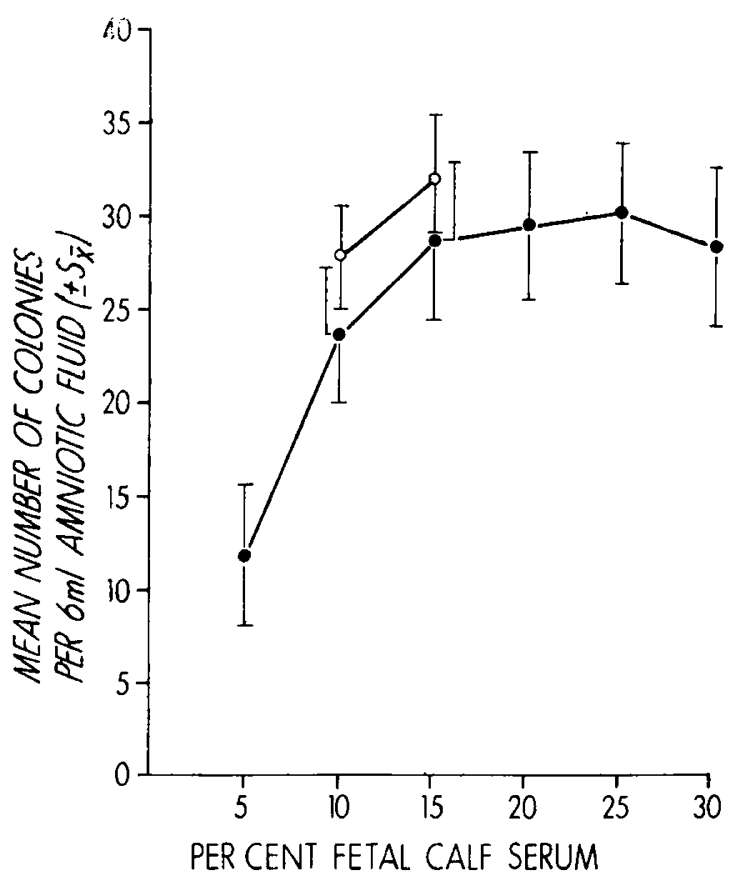

Fig. 1. Mean number of colonies cultured from $6 \mathrm{ml} \mathrm{AF} \mathrm{(} \pm$ SDM) at each FCS concentration. The preliminary experiment $(\bullet)$ contained 17 experimental blocks, and the supplementary experiment $(0)$ contained 51 experimental blocks.

Table 1. Preliminary fetal calf serum (FCS) experiment: pairwise differences in colonies per $6 \mathrm{ml}$ cultured $A F$ analyzed by Student-type range procedure ${ }^{1}$

\begin{tabular}{|c|c|c|c|c|c|c|}
\hline \multirow[b]{2}{*}{ FCS, $\%$} & \multicolumn{6}{|c|}{ FCS, $\%$} \\
\hline & 5 & 10 & 15 & 20 & 25 & 30 \\
\hline 5 & & $11.83^{2}$ & $16.94^{2}$ & $17.83^{2}$ & $1859^{2}$ & $16.83^{2}$ \\
\hline 10 & & & $5.12^{3}$ & $6.00^{4}$ & $6.76^{5}$ & $5.00^{3}$ \\
\hline 15 & & & & 0.89 & 1.65 & 0.11 \\
\hline 20 & & & & & 0.76 & 1.00 \\
\hline 25 & & & & & & 1.76 \\
\hline 30 & & & & & & \\
\hline
\end{tabular}

${ }^{1}$ For example, the 11.83 shows that the mean number of colonies per $6 \mathrm{ml}$ amniotic fluid cultured in $10 \% \mathrm{FCS}$ is 11.83 colonies $/ 6 \mathrm{ml}$ greater than the mean number of colonies per $6 \mathrm{ml}$ in $5 \% \mathrm{FCS}$.

${ }^{2}$ Significant at the 0.0005 level of significance.

${ }^{3}$ Significant at the 0.10 level of significance using Newman-Keuls' modification.

${ }^{4}$ Significant at the 0.05 level of significance using Newman-Keuls' modification (9) in which the $5 \%$ FCS data are excluded from analysis.

${ }^{5}$ Significant at the 0.05 level of significance.

\section{SUPPLEMENTARY EXPERIMENT (10\% VERSUS 15\% FCS)}

The difference between the means for 10 and $15 \% \mathrm{FCS}$, 5.12 colonies $/ 6 \mathrm{ml}$, was found to be significant at the 0.10 level. In order to verify this difference at the 0.05 level of significance, a supplementary experiment was done (15). Twenty-eight AFs were used to obtain 51 additional blocks. The mean number of colonies per $6 \mathrm{ml} \mathrm{AF}$ obtained with $10 \%$ FCS was 27.8 , and with $15 \%$ FCS, 32.1. The population SD was 7.25. The $t$ value for comparison of the means was significant $(t=2.99, P<0.01)$. Utilizing a 95\%, one-sided confidence interval, we conclude that the mean number of colonies per $6 \mathrm{ml} \mathrm{AF}$ in $15 \%$ FCS was at least 1.88 greater than the mean number of colonies per $6 \mathrm{ml} \mathrm{AF}$ in $10 \% \mathrm{FCS}$.

\section{CORRELATION OF OTHER VARIABLES WITH NUMBER OF COLONIES}

Data were pooled from 76 AF specimens used in the FCS and other block design experiments, all of which fulfilled specific "control" conditions: (1) nonbloody AF obtained before saline-induced abortion; (2) AF cultured in $35-\mathrm{mm}$ plastic petri dishes; (3) F10 medium with 20\% FCS (routine medium before completion of FCS study); (4) all AFs subjected to the same method of initial inoculation and subsequent medium changes.

Cell growth was obtained from every cultured AF and there was no bacterial contamination. The number of colonies cultured per milliliter AF among the 76 specimens ranged between 1.3 and 12.8 colonies/ml (SD 2.99). The average volume of AF examined was $7 \mathrm{ml}$ (range, 2-18 ml). By giving equal weight to the estimates from each $\mathrm{AF}$ specimen, the mean was 5.7 colonies $/ \mathrm{ml} \mathrm{AF}\left(\mathrm{SD}_{\bar{x}} 0.32\right)$. By weighting each estimate according to the volume of AF from which it was derived, the mean was 6.0 colonies $/ \mathrm{ml} \mathrm{AF}$.

Four variables were tested for correlation with the mean number of colonies formed per milliliter AF.

Gestational Age. Gestational age can be estimated from the date of the last menstrual period (LMP) and from fetal measurements $(13,14)$. Fetal foot length was measured for 21 abortuses and the resultant age estimate was correlated with the LMP age estimate $(\mathrm{r}=0.546, P<0.01)$. LMP gestational age estimates were considered acceptable for examining the effect of gestational age on AF cell growth.

Sixty-nine cultures, 11-24 weeks of gestational age, were classified by LMP gestational age and by the mean number of colonies per milliliter, AF, into approximately equally sized groups to facilitate analysis (Table 2). A standard chi square goodness of fit test was performed to evaluate the hypothesis that the mean number of colonies per milliliter AF is independent of gestational age. The chi square value of 6.73 was insignificant $(0.25<P<0.50)$, hence the data were consistent with the independence hypothesis.

A power study (1) of these data, done to estimate the probability of rejecting a "false" hypothesis, stated: (1) at a 0.15 level of significance for the chi square test, there was at least a 0.50 power value for detecting an average difference of 2.0 colonies $/ \mathrm{ml}$ AF for at least one of the age groups; (2) evaluation of $250 \mathrm{AFs}$ would be required to detect an average difference of 2.0 colonies $/ \mathrm{ml} \mathrm{AF}$ for at least one of the age groups with a power of 0.90 and a 0.05 level of significance.

Maternal Age. The AFs were similarly grouped for a test of independence between maternal age $(14-42$ years) and mean

Table 2. Amniotic fluid (AF) specimens classified by gestational age and cell growth for chi square analysis 1

\begin{tabular}{ccccc}
\hline & \multicolumn{4}{c}{ Mean number of colonies/ml AF } \\
\cline { 2 - 5 } $\begin{array}{c}\text { Gestational } \\
\text { age, wk }\end{array}$ & $0-3.9$ & $4.0-5.9$ & $5.9-10.0$ & Total \\
\hline$\geqslant 11,<16$ & 5 & 4 & 2 & 11 \\
& $(3.188)$ & $(3.188)$ & $(4.624)$ & \\
$\geqslant 16,<17$ & 7 & 3 & 6 & 16 \\
& $(4.638)$ & $(4.638)$ & $(6.724)$ & \\
$\geqslant 17,<19$ & 4 & 7 & 11 & 22 \\
& $(6.377)$ & $(6.377)$ & $(9.246)$ & \\
$\geqslant 19,<24$ & 4 & 6 & 10 & 20 \\
& $(5.797)$ & $(5.797)$ & $(8.406)$ & \\
Total & 20 & 20 & 29 & 69 \\
\hline
\end{tabular}

${ }^{1}$ The number of $\mathrm{AF}$ specimens expected in each class is given in parentheses below the observed number. Chi square value $=6.73$ with $0.25<P<0.50$. 
number of colonies per milliliter AF. The chi square value was $5.30(0.05<P<0.70)$, hence no significant difference was demonstrated. The power study for this test yielded the same statements given above for gestational age.

Ethnic Group. Forty-four of the AFs could be classified by maternal ethnic group (Negro or Caucasian) and mean number of colonies per milliliter AF. A chi square test for independence gave a value of 3.28 and was not significant $(0.10<P<$ 0.20 ). Using a 0.05 level of significance, there was at least a 0.50 power for detecting an average difference of 2.0 colonies/ml AF between the two groups.

Time Interval between Amniocentesis and Culture. Most cultures were initiated within $8 \mathrm{hr}$ and the mean number of colonies appeared to be unchanged throughout this interval. However, AFs processed during the first $3 \mathrm{hr}$ were obtained from one hospital where 13-gauge needles were used for amniocentesis (group I). AFs processed during the 3-8 $\mathrm{hr}$ interval were obtained from a second hospital where 14-gauge needles were used, and transported to us by messenger service (group II). The number of colonies per milliliter ranged between 1 and 12 in group $I\left(\mathrm{~s}_{\mathrm{J}}{ }^{2}=11.36\right)$, and between 4 and 9 in group $I I\left(\mathrm{~s}_{\mathrm{II}}{ }^{2}=2.85\right)$. These variance estimates were significantly different $(\mathrm{F}=3.99, P<0.0005)$. No interpretation is possible because of the three compounding variables. This finding emphasizes that all conditions surrounding amniocentesis and culture may affect optimal growth of AF cells.

\section{DISCUSSION}

A primary objective of the FCS experiments was to develop an experimental design appropriate for evaluating growth of AF cells in culture. We wished to establish the size of experiments needed to make statistically valid, quantitative statements about effects of cell culture variables.

We have observed significant variation in number of colonies per milliliter AF among specimens and have found a randomized, multivariable block design to be most efficient in obtaining data for assessing AF cell culture. In this design, all experimental manipulations are performed on equal aliquots of each AF used in an experiment. Randomization of each procedure which could introduce bias is necessary. The close agreement of the SD estimates of the preliminary and supplementary experiments indicates that the assumptions required for our experimental design are correct and that technical procedures are highly reproducible.

Number and size of colonies are more discriminating and more objective measures of culture "success" than subjective criteria reported in the literature, e.g., time to the first cell division (12), number of culture failures (11), time required for biochemical or cytogenetic results (4), and degree of confluency (6). None of these criteria documents the number of cells attached initially or the number of resultant colonies. For example, if we had classified our results as culture success or failure, we could not have demonstrated a growth difference among $5-30 \%$ FCS.

Our results contradict a study (8) which demonstrated no difference in numbers of colonies $(>6$ cells) after 7 days of culture when AF cells were grown in 1 part AF and 1 part medium, with a final concentration of $5,7.5$, and $15 \%$ FCS. The serum components in AF plus the additional FCS may have provided optimal serum concentration. However, AF composition is variable and some AFs do not sustain cell growth when cells from the same AF can be successfully cultured in medium plus FCS (2).

The factor or factors present in FCS which are necessary for culturing human diploid cells have not been defined. It has been generally observed that lots of commercially prepared FCS differ in their growth-promoting properties. We pretest each FCS lot by comparing the cloning efficiency of a normal human diploid cell culture, recently thawed from liquid $\mathrm{N}_{2}$, in medium containing a test lot of FCS and in medium containing the FCS currently in use (control). Five milliliters of a cell suspension, prepared as 20 cells $/ \mathrm{ml}$ in F10 with each FCS lot, is inoculated into each of $1060-\mathrm{mm}$ diame ter culture dishes. The culture medium is changed every $3-4$ days and the resultant colonies are stained and counted at 10 days. Six lots have recently been tested and analyzed by $t$ test. Two were rejected because they supported approximately one-half the number of colonies as did the control.

We have assumed that different, pretested FCS lots have similar curves describing number of colonies versus FCS concentration. One FCS lot was used for the preliminary, and a second for the supplementary experiment. The difference between 10 and $15 \%$ FCS is similar in each experiment. The two means at $10 \%$ are significantly different $(P<0.0001)$ and the two means at $15 \%$ are significantly different $(P<0.0001)$, which demonstrates differences in growth-supporting properties between FCS lots.

The concentration of total cells and "viable" cells increases approximately 60 -fold between 11 and 24 weeks of gestational age (5). We have demonstrated that the number of colonies formed per milliliter AF is independent of gestational age within this range, and thus is not an important factor in timing an amniocentesis for prenatal diagnostic cell culture. Dye exclusion "viability" is not a reliable indicator of AF culture success.

Refinements now being added to this experimental design allow evaluation of frequency of attachment and rates of early cell division for different morphological AF cell types. These procedures should yield a more complete assessment of the effect of culture variables.

\section{SUMMARY}

The number of colonies obtained by culturing undiluted AF cells can be a sensitive and reliable measure of AF culture success. A randomized, multivariable block design is most efficient, since there is significant variation in numbers of colonies cultured per milliliter of AF among specimens. Efficiency is further increased by determining, from a preliminary experiment, the number of blocks required for formulation of meaningful statistical statements. Comparison of our preliminary and supplementary experiments documented that we have made valid experimental assumptions and that our technical procedures are reproducible.

In demonstrating this design, we have shown that $15 \%$ FCS in F10 medium supports optimal cell growth. Examination of 76 AF cultures has documented that AF cell growth is independent of gestational age, maternal age, and maternal ethnic origin.

\section{REFERENCES AND NOTES}

1. Davis, H. T.: Power of the Chi-square test of homogeneity for a 3 $X \mathrm{k}$ against a shift alternative (Technical Report $I$, Division of Biostatistics, University of Rochester, N. Y., 1974.

2. Doherty, R. A., Felix, J. S., and Ridge, S. C.: Amniotic fluid cell culture. II. Effects of centrifugation, culture surface and cleaning procedure (in preparation).

3. Feder, P. I.: Studentized range graph paper - a new tool for the graphical comparison of treatment means (General Electric Information Series, Report no. 72CRD193, Corporate Research and Development Distribution, Schenectady, N. Y., 1972).

4. Gray, C., Davidson, R. G., and Cohen, M. M.: A simplified technique for the culture of amniotic fluid cells. J. Pediat., 79: 119 (1971).

5. Hahneman, N.: Possibility of culturing foetal cells at early stages of pregnancy. Clin. Genet., 3:286 (1972).

6. Kaback, M. M., and Leonard, C. O.: Morphological and enzymological considerations in antenatal diagnosis. In: A. Dorfman: Antenatal Diagnosis, p. 81 (University of Chicago Press, Chicago, 1972).

7. Knörr-Gartner, H., and Härle, I.: A modified method of culturing 
human amniotic fluid cells for prenatal detection of genetic disorders. Humangenetik, 114: 333 (1972).

8. Marchant, G. S.: Evaluation of methods of amniotic fluid cell culture. Amer. J. Med. Technol., 37: 391 (1971).

9. Miller, R. G., Jr.: Simultaneous Statistical Inference (McGraw-Hill, New York, 1966).

10. Milunsky, A.: The Prenatal Diagnosis of Hereditary Disorders (Charles C Thomas, Publisher, Springfield, Ill., 1973).

11. Nelson, M. M., and Emery, A. E. H.: Amniotic fluid cell culture. J. Med. Genet., 10: 19 (1973).

12. Niermeijer, M. F., Halley, D., Sachs, E., Tichelaar-Klepper, C., and Garver, K. L.: Transport and storage of amniotic fluid samples for prenatal diagnosis of metabolic diseases. Humangenetik, 20: $175(1973)$.

13. Shepard, T. H.: Normal and abnormal growth patterns. In: L. I. Gardner: Endocrine and Genetic Diseases of Childhood, p. 1 (W. B. Saunders Co., Philadelphia, 1969).

14. Streeter, G. L.: Weight, sitting height, head size, foot length and menstrual age of the human embryo. Contrib. Embryo. Carnegie Inst. 11: 143 (1921).

15. To plan a supplementary experiment, it was assumed that the SD and the mean difference between 10 and $15 \%$ FCS would be of the order indicated by the preliminary experiment. It was stipulated that an increase of at least 2 colonies $/ 6 \mathrm{ml}$ would be required for significance. The mean difference of 5.12 would then have a one-sided confidence interval of approximately 3 . By inverting the usual $t$ statistic or by use of Studentized range graph paper, we estimated that another experiment with approximately 40 blocks, using only 10 and $15 \% \mathrm{FCS}$, should detect such a difference at a 0.05 level of significance.

16. Wheaton Glass Co., Millville, N. Y., catalog no. 20545.

17. Falcon Plastics, Oxnard, Calif., catalog no. 3001

18. Wedco, Inc., Silver Springs, Md., model no. 2-17M.

19. Grand Island Biological Co., Grand Island, N.Y.

20. Radiometer, Copenhagen, $\mathrm{pH}$ meter no. 22, microelectrode no. 5021 , London Co., Cleveland, Ohio.

21. These studies were reviewed and approved by the Committee on Investigations Involving Human Subjects, University of Rochester School of Medicine and Dentistry, Rochester, N. Y.

22. We wish to thank the numerous obstetricians and nurses who provided us with AF specimens.

23. This work was supported by a grant from The John A. Hartford Foundation, Inc., and by NIH/GSRR RR 05403. Part of the work was performed in facilities of the United States Atomic Energy Commission at the University of Rochester Atomic Energy Project and has been assigned Report no. UR-3490-496.

24. Requests for reprints should be addressed to: R. Doherty, M. D., Department of Pediatrics, University of Rochester School of Medicine, Rochester, N. Y. 14642 (USA).

25. Accepted for publication July $2,1974$.

\title{
Studies on the Biosynthesis of Disaturated Lecithin of the Lung: The Importance of the Lysolecithin Pathway
}

\author{
MIKKO HALLMAN AND KARI RAIVIO(31) \\ Department of Pediatrics, University of Helsinki, Helsinki, Finland
}

\section{Extract}

The formation of disaturated lecithin in lung slices obtained from adult rabbit was studied. Radioactive precursors of the known biosynthetic pathways of lecithin were used.

Cytidine diphospho- $\left(\right.$ methyl- $\left.{ }^{14} \mathrm{C}\right)$ choline (CDP- $\left({ }^{14} \mathrm{C}\right)$ choline) was the marker of the choline incorporation pathway. The label rapidly appeared in lecithins and subsequently in lysolecithin. As a function of time, the ratio of label in disaturated to total lecithin increased significantly. When the slices were preincubated with the radioactive precursor and then with excess nonradioactive precursor, the fraction of total lecithin radioactivity associated with disaturated species increased from 14.2 to $24.0 \%$ in $120 \mathrm{~min}$.

Lecithin labeled with $\left(1(3)-{ }^{3} \mathrm{H}\right)$ glycerol and $\left(1-{ }^{14} \mathrm{C}\right)$ palmitic acid and containing a high percentage of unsaturated fatty acids was incubated with lung slices. After $1 \mathrm{hr}$, the ratio of ${ }^{14} \mathrm{C}$ label in disaturated to total lecithin nearly doubled, and ${ }^{14} \mathrm{C}$ and ${ }^{3} \mathrm{H}$ in disaturated lecithin increased by $58 \%$ and $21 \%$, respectively.

After $60 \mathrm{~min}$ of incubation of liver slices with 1-acyl-2-lyso- lecithin labeled with $\left(1(3)-{ }^{3} \mathrm{H}\right)$ glycerol and $\left(1-{ }^{14} \mathrm{C}\right)$ palmitic acid, the ratio of the ${ }^{3} \mathrm{H}$ label in lecithin to lysolecithin was 2.0. In disaturated lecithin the ratio of ${ }^{3} \mathrm{H}$ to ${ }^{14} \mathrm{C}$ radioactivity was less than half of that in lysolecithin, and $61 \%$ of ${ }^{14} \mathrm{C}$ radioactivity was associated with fatty acid esterified to position 2.

Using $S$-adenosyl (methyl- ${ }^{3} \mathbf{H}$ ) methionine or phosphatidylethanolamine labeled with $\left(1(3)-{ }^{3} \mathrm{H}\right)$ glycerol and $\left(1-{ }^{14} \mathrm{C}\right)$ palmitic acid as precursors, the radioactivity appeared rapidly and almost exclusively in unsaturated lecithins and reached a maximum after $60 \mathrm{~min}$ of incubation. Thereafter the specific activity of lecithin fell to half of its maximal value within 90 min. Lysolecithin became heavily labeled.

The data suggest that in lung slices obtained from adult rabbit a modification of the lecithin fatty acids takes place. Hydrolysis of an unsaturated fatty acid esterified to position 2 is followed by reacylation with a saturated fatty acid, possibly by a transacylation reaction from position 1 of another 1-acyl-2-lysolecithin molecule, to form disaturated lecithin. The choline incorporation pathway of de novo formation of lecithin appears to combine with such a lysolecithin "loop" to 